\title{
Magnesium and Ketamine Gargle and Postoperative Sore Throat
}

\author{
Houman Teymourian ${ }^{1, *} ;$ Seyed Amir Mohajerani ${ }^{1}$; Alireza Farahbod ${ }^{1}$ \\ ${ }^{1}$ Department of Anesthesiology, Shohada Hospital, Shahid Beheshti University of Medical Sciences, Tehran, Iran \\ *Corresponding author: Houman Teymourian, Department of Anesthesiology, Shohada Hospital, Shahid Beheshti University of Medical Sciences, Tehran, Iran. Tel/ \\ Fax: +98-2122343657, E-mail: houman72625@yahoo.com
}

Received: September 16, 2014; Revised: December 16, 2014; Accepted: December 25, 2014

\begin{abstract}
Background: Postoperative sore throat is one of the most common complications after endotracheal intubation. Both Ketamine and magnesium can block N-methyl-D-aspartic acid (NMDA) receptors and provide central and local analgesia.

Objectives: To compare the effect of magnesium sulfate and ketamine gargle on the incidence and severity of postoperative sore throat. Patients and Methods: A total of 100 patients candidate for emergency acute appendicitis surgery were enrolled in the study. Patients in ketamine group received ketamine gargle $(0.5 \mathrm{mg} / \mathrm{kg})$ and magnesium group received magnesium sulfate gargle $(20 \mathrm{mg} / \mathrm{kg} \mathrm{up} \mathrm{to} 30 \mathrm{~mL}$ dextrose water 20\%) 15 minutes before the operation. Patient complaint of postoperative sore throat, and its severity measured by visual analogue scale (VAS) were recorded at baseline in recovery room, and then 2,4 , and 24 hours after operation.

Results:There were nosignificant differences betweenage,sex, and body massindex(BMI) between two groupsof patients. Hemodynamics of patients, including blood pressure, respiratory rate, oxygen saturation \%, and conscious state were not significantly different $(\mathrm{P}>0.05)$. Number of patients with sore throat were significantly lower in magnesium group compared to ketamine group at $2(\mathrm{P}=0.032), 4(\mathrm{P}=$ $0.02)$, and 24 hours $(\mathrm{P}=0.01)$ after the operation. Sore throat pain score $(\mathrm{VAS})$ was significantly lower in magnesium group compared to ketamine group at $2(\mathrm{P}=0.019), 4(\mathrm{P}=0.028)$, and 24 hours $(\mathrm{P}=0.014)$ after the operation.

Conclusions: Magnesium at low dose decreases sore throat and pain severity more effectively compared to ketamine gargle.
\end{abstract}

Keywords: Ketamine; Magnesium; Postoperative Complications; Sore Throat; Pain

\section{Background}

Postoperative sore throat is one of the most common complications of patients after endotracheal intubation (1), which usually lingers for 12 - 24 hours after the operation. The incidence is estimated to be of $18 \%$ - $65 \%$ in different studies (2). Several risk factors, including head and neck surgery, female gender (3), postoperative nausea and vomiting and harsh intubation have been reported as the causes of postoperative sore throat (4). Despite little attention to this complication, it is one of the main causes of patients' dissatisfaction after surgery (5). Smooth laryngoscopy and intubation against harsh intubation, adaptive endotracheal tubes, cuff design, minimizing cuff pressure, and use of high dose cisatracurium instead of succinylcholine for rapid sequence intubation (6) are meant to decrease trauma. Widespread recognition of the undertreatment of sore throat by clinicians has led to the development of preemptive strategies for its alleviation.

Although many preventive protocols have been offered, none has gained much attention. However, drug based preemptive analgesia is the mainstay of treatment for postoperative sore throat. Multimodal analgesia and judicious use of adjuvant agents, such as nonsteroidal antiinflammatory drugs, lidocaine, and beclomethasone may improve postoperative analgesia and diminish analgesic- related side effects (7). Today's clinical pharmacy could enhance our knowledge in practicing other drugs without direct analgesic effects such as magnesium or ketamine. Both ketamine and magnesium can block N-methyl-Daspartic acid (NMDA) receptors. However, there are not enough studies on their direct local analgesic effect.

\section{Objectives}

In this study, we aimed to compare the effect of magnesium sulfate and ketamine gargle on the incidence and severity of postoperative sore throat.

\section{Patients and Methods}

\subsection{Study Design}

This study was a randomized clinical trial. The study was reviewed and approved by Shahid Beheshti Medical University Review Board and Shohada Hospital Ethics Committee. Information about the study was given comprehensively both orally and in written form to the patients. All patients gave their written informed consents prior to their inclusion in the study according to University Hospital Ethics Board Committee. 


\subsection{Patient Selection}

A total number of 100 patients with American Society of Anesthesiologist (ASA) class 1, 2 candidate for emergency acute appendicitis surgery and age ranges 25 - 75 years were enrolled in the study and randomly allocated to ketamine or magnesium groups. Exclusion criteria were history of sore throat before operation, allergies to ketamine and magnesium, more than one attempt laryngoscopy, consumption of analgesic in preoperative period, nausea and vomiting before operation, any perioperative complications, and duration of operation more than 2 hours.

\subsection{Primary and Secondary Outcome}

Primary outcome was sore throat. Secondary outcome was pain scale measured by visual analogue scale (VAS) scores.

\subsection{Ketamine and Magnesium Gargle}

Patients in ketamine group received ketamine gargle (8) $(0.5 \mathrm{mg} / \mathrm{kg}$ ketamine in $30 \mathrm{~mL}$ dextrose water $20 \%)$ and magnesium group received magnesium sulfate gargle (20 mg/kg magnesium sulfate up to $30 \mathrm{~mL}$ dextrose water 20\%) 15 minutes before operation. Pharmacological formula for used medication contains ketamine hydrochloride (Rotexmedica, Tritau, Germany) and magnesium sulfate 50\%(Infu-Magnesol, Shahid Ghazi Pharmaceutical Co, Iran).

\subsection{Induction and Maintenance of Anesthesia}

After administration of ketamine and magnesium gargle, patients were monitored for ECG, oxygen saturation (SPO2\%), noninvasive blood pressure (NIBP), and train of four (TOF) after entering to the operation room. After monitoring, patients were pre-oxygenated with $5 \mathrm{~L} / \mathrm{min}$ $\mathrm{O}_{2} 100 \%$ for 3 to 5 minutes. For pre-medication, midazolam $0.02 \mathrm{mg} / \mathrm{kg}$ and fentanyl $2 \mu \mathrm{g} / \mathrm{kg}$ were administered. Three minutes later, rapid sequence induction was performed by administration of $5 \mathrm{mg} / \mathrm{kg}$ thiopental and 1.5 $\mathrm{mg} / \mathrm{kg}$ succinylcholine. Intubation was performed under smooth direct laryngoscopy after 60 - 90 seconds when TOF $=0$. Endotracheal tube size was selected after laryngoscopy under direct visualization.

All intubations were performed by the same anesthesiologist. Patients would be excluded from the study if intubation failed after second attempt, or intubation was difficult, or $\mathrm{O}_{2}$ saturation was less than 95\%. Endotracheal tube cuff was inflated until no exhalation sounds or leak were heard. Besides inflated cuff was measured using a standard gage at $20-30 \mathrm{~cm} \mathrm{H}_{2} \mathrm{O}$. Maintenance of anesthesia was the same in both group using isoflurane $1 \mathrm{MAC}$ and cisatracurium and $\mathrm{O}_{2} 50 \% / \mathrm{N}_{2} \mathrm{O} 50 \%$. Extubation was performed using the same method in both groups; after surgery, when TOF $>0.7$ and patient was fully awaked, neuromuscular block was reversed (neostigmine $0.05 \mathrm{mg} / \mathrm{kg}$ plus atropine $>0.02 \mathrm{mg} / \mathrm{kg}$ ) and extubated. If patients had several bucking during extubation, they would be excluded from study. In recovery room, patients only received $\mathrm{O}_{2} 5 \mathrm{~L} / \mathrm{min}$ via face mask. If postoperative pain VAS $\geq 4$, then an appropriate analgesic was administered.

\subsection{Data Collection}

Patient complaint of sore throat and severity of its pain measured by visual analogue scale (VAS) were recorded at baseline in recovery room and then at 2, 4, and 24 hours after operation with a specified questionnaire. All those variables were measured using positive or negative (yes/ no) questions. If VAS was equal or greater than 5 at any time, analgesics would be administered.

\subsection{Statistical Analysis}

Statistical calculations were conducted using SPSS 20 (Chicago, IL, USA). The parametric variables were presented as mean \pm SD and analyzed by Student $t$ test or ANOVA and Pearson correlation test as appropriate. Statistical analysis was performed using Chi-square or Mann-Whitney $U$ test and Spearman correlation coefficients was performed for non-parametric samples. $\mathrm{P}<0.05$ was considered as statistically significant. Sample size was estimated using sample size calculator software with $95 \%$ confidence interval, $\mathrm{P}=0.05$, power of $80 \%$, and difference between two groups of $20 \%$ in primary outcome (sore throat) based on pilot study.

\section{Results}

A total of 100 patients were included in the study and randomly assigned to one of the groups. Fifty patients received ketamine and 50 received magnesium. There were no significant differences between two groups of patients with respect to age, sex, and BMI (Table 1). Duration of surgery was not significantly different between two groups $(\mathrm{P}=0.032)$. Hemodynamics of patients was also compared and blood pressure, respiratory rate, oxygen saturation \%, and conscious state were not significantly different between two groups (Table 2). Incidence of postoperative sore throat in two groups after using magnesium or ketamine gargle were not significantly different at arrival in the recovery ward $(\mathrm{P}=0.085)$. However, number of patients with sore throat were significantly lower in the magnesium group compared to ketamine group at $2(\mathrm{P}=0.032), 4(\mathrm{P}=0.02)$, and 24 hours $(\mathrm{P}=0.01)$ after operation (Chi-square test). It seems that magnesium had longer time effective analgesia than that of the ketamine (Figure 1). Sore throat pain score was measured by visual analogue scale (VAS) was not significantly different between two groups of study at 0 hour $(P=0.013)$. However, sore throat pain score (VAS) was significantly lower in magnesium group compared to ketamine group at $2(\mathrm{P}=0.019), 4(\mathrm{P}=0.028)$, and 24 hours $(\mathrm{P}=0.014)$ after operation (Figure 2$)$. 
Table 1. Demographic Characteristics of Patients in Two Groups of Study ${ }^{a}$

\begin{tabular}{lccc}
\hline Variables & Magnesium & Ketamine & PValue \\
\hline Age, $\mathbf{y}$ & $27.6 \pm 11.5$ & $26.3 \pm 10.2$ & 0.34 \\
Male, \% & 55 & 52.5 & 0.28 \\
\hline Weight, Kg & $72.3 \pm 18.2$ & $73.3 \pm 17.7$ & 0.30 \\
BMI, kg/m & $21.2 \pm 4.3$ & $22.6 \pm 3.6$ & 0.26 \\
$\begin{array}{l}\text { Duration of intu- } \\
\text { bation, min }\end{array}$ & $52.5 \pm 23.4$ & $55.8 \pm 21.2$ & 0.12 \\
\hline
\end{tabular}

${ }^{\mathrm{a}}$ Data are presented as mean $\pm \mathrm{SD}$.

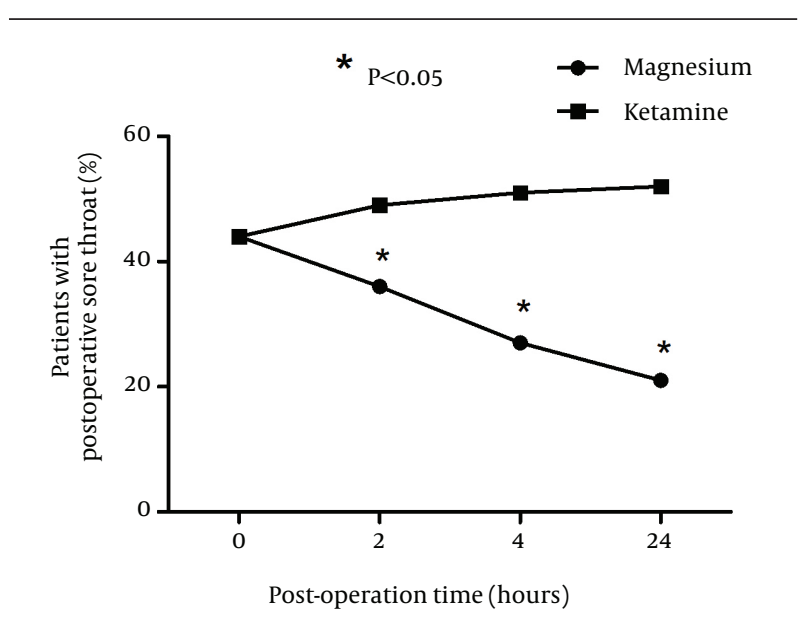

Figure 1. Incidence of Postoperative Sore Throat in Two Groups at Different Time Points After Administration of Magnesium or Ketamine Gargle

\section{Discussion}

In this study, magnesium and ketamine effect in controlling postoperative sore throat were compared. Incidence and severity of postoperative sore throat were significantly lower in magnesium group compared to ketamine gargle group. In our discussion, we attempted to elaborate the pharmacological mechanism of this important finding to be used in clinical pharmacology. Incidences of postoperative sore throat were compared at different time points in magnesium and ketamine gargle groups. Magnesium showed a superior effect in decreasing sore throat incidence after surgery. Apparently, magnesium at the dose of $20 \mathrm{mg} / \mathrm{kg}$ is more effective in controlling postoperative sore throat but ketamine did not show the same effect. Using broader definition of preventive analgesia, the comparison of magnesium and ketamine gargle and positive clinical effect of magnesium strongly suggest that preemptive analgesic effect of magnesium gargle is a more clinically relevant phenomenon compared to ketamine gargle.
Table 2. Comparison of Hemodynamic, Oxygen Saturation and Conscious Status of Patients Between Magnesium and Ketamine Group $^{\mathrm{a}}$

\begin{tabular}{|c|c|c|c|}
\hline Variables & $\begin{array}{l}\text { Magne- } \\
\text { sium }\end{array}$ & Ketamine & $\begin{array}{c}P \\
\text { Value }\end{array}$ \\
\hline Heart rate, beat/min & $87.75 \pm 15.39$ & $91.25 \pm 18.34$ & 0.085 \\
\hline $\begin{array}{l}\text { Systolic blood pres- } \\
\text { sure, mmHg }\end{array}$ & $134.4 \pm 28.53$ & $\begin{array}{c}129.55 \pm \\
24.65\end{array}$ & 0.16 \\
\hline $\begin{array}{l}\text { Respiratory rate, } \\
\text { breath/min }\end{array}$ & $12.6 \pm 4.3$ & $12.2 \pm 4.9$ & 0.33 \\
\hline Oxygen saturation, \% & $97.2 \pm 3.1$ & $97.2 \pm 2.5$ & 0.25 \\
\hline Consciousness status & Alert, Obey & Alert, Obey & NA \\
\hline
\end{tabular}

${ }^{\mathrm{a}}$ Data are presented as mean \pm SD.

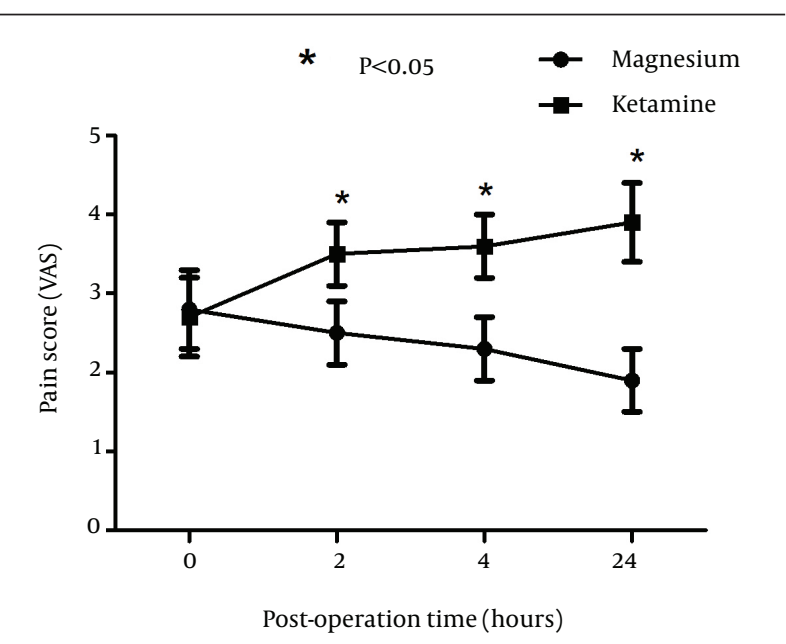

Figure 2. Comparison of Sore Throat Pain Score (Visual Analogue Scale or VAS) Between Magnesium and Ketamine Group

Ketamine gargle analgesic effect in sore throat has been matter of discrepancy in previous studies. In our study, ketamine gargle $(0.5 \mathrm{mg} / \mathrm{kg})$ effect was not significant in decreasing the incidence of postoperative sore throat in our study. Patients vary tremendously in their response to ketamine gargle analgesic effects. In another study, ketamine gargle reduces the incidence of postoperative sore throat after endotracheal intubation $(9,10)$. However, in other studies, only higher dose of ketamine (50 $\mathrm{mg}$ in $29 \mathrm{~mL}$ water) was shown to be effective (11). Another study demonstrated improved analgesic effects after using intravenous patient controlled analgesia with ketamine on postoperative pain in opium abusers (12). Some other studies have shown that addition of ketamine to intravenous fentanyl plus acetaminophen PCA did not have extra effects in relieving post abdominal surgery pain (13). Gargling with ketamine (40 mg in $30 \mathrm{~mL}$ normal saline) before induction of anesthesia is comparable 
with application of $0.05 \%$ betamethasone gel over the endotracheal tubes in decreasing postoperative sore throat (14). However, increase in ketamine dose could increase incidence of ketamine adverse effects.

Ketamine and magnesium both can block N-methylD-aspartic acid (NMDA) receptor. Ketamine relaxes the tracheal muscle contraction through a mechanism independent of NMDA receptors. In addition, the decreased bronchomotor tone induced by ketamine is probably due to its interference with $\mathrm{Ca}^{2+}$ (a required step necessary to maintain the contraction). In this sense, magnesium could probably block the $\mathrm{Ca}$ entrance to tracheal muscle in a more effective manner (15). Recent reports of the incidence of postoperative sore throat following anesthesia have claimed that the incidence of postoperative sore throat does not necessarily reflect damage caused by the tracheal tube cuff but more of increased muscle contracture (16). By preventing central sensitization, preemptive analgesia along with intensive multimodal analgesic interventions could theoretically reduce postoperative sore throat incidence and severity (17). Another important result of our study was that sore throat pain score (visual analogue scale or VAS), which was significantly lower in magnesium compared to ketamine group. It is important to know that preemptive analgesia is part of the bigger picture of decreasing pain. In fact, the severity of pain is also reduced in magnesium group but not in ketamine group. Probably analgesic effect is performed through both local effect and through central effect. Various reports have shown that ketamine and magnesium gargle effects are performed through local nociception not systemic effect. Sore throat and hoarseness occur after total intravenous anesthesia with ketamine (18) that shows systemic effect is not of much importance in alleviating sore throat. In fact, intravenous injection of low dose ketamine is not effective in reducing postoperative sore throat (19). In addition, previous reports insisted on lesser analgesic systemic levels of ketamine.

Piriyapatsom et al. study (20) showed that ketamine level after gargle reaching $16 \mathrm{ng} / \mathrm{mL}$, which is less than analgesic dose, could control pain for only 2 hours. This was consistent with our results, which ketamine gargle controlled pain for only 2 hours. Altogether it seems that both ketamine and magnesium induce their effect through local circuits than systemic effect; in that regard magnesium is more effective than ketamine. Definitions of preemptive analgesia include medications administer before the surgical incision, what prevents the establishment of central sensitization resulting from incisional injury and inflammatory injury (i.e. intraoperative and postoperative periods), or the entire perioperative period. Maximum clinical benefit was observed when there was complete blockade of noxious stimuli with extension of this block into the postoperative period, which was after 24 hours. This means that both ketamine and magnesium effects are performed through local effect and therefore increase in their doses do not increase their effect.
There are some limitations to our study too. In patient selection, it was better to choose them from an elective surgery instead of an emergency one. Using succinylcholine itself could be a source of sore throat. Also, after 24 hours, there are other factors that can affect the sore throat such as NPO time after surgery or the amount of pain killer given to the patient for surgery site, which needs to be modified in future studies. In conclusion, magnesium gargle seems to be a safe and easy analgesic approach for decreasing postoperative sore throat. Magnesium at low dose decreases sore throat and pain severity more significantly compared to ketamine gargle. This study provides appropriate example of using clinical pharmacology in clinical settings.

\section{Acknowledgements}

The authors of this article declared no conflict of interest, no consulting, or personal relationships with any other people or organizations that could influence (bias) the author's work.

\section{Authors' Contributions}

Dr. Houman Teymourian suggested the study design, performed critical revision and manuscript approval. Dr. Alireza Farahbod performed data collection. Dr. Seyed Amir Mohajerani performed manuscript drafting, data analysis, and statistics interpretation.

\section{References}

1. Jensen PJ, Hommelgaard P, Sondergaard P, Eriksen S. Sore throat after operation: influence of tracheal intubation, intracuff pressure and type of cuff. BrJ Anaesth. 1982;54(4):453-7.

2. Chandler M. Tracheal intubation and sore throat: a mechanical explanation. Anaesthesia. 2002;57(2):155-61.

3. Jaensson M, Gupta A, Nilsson UG. Gender differences in risk factors for airway symptoms following tracheal intubation. Acta Anaesthesiol Scand. 2012;56(10):1306-13.

4. McHardy FE, Chung F. Postoperative sore throat: cause, prevention and treatment. Anaesthesia. 1999;54(5):444-53.

5. Porter NE, Sidou V, Husson J. Postoperative sore throat: incidence and severity after the use of lidocaine, saline, or air to inflate the endotracheal tube cuff. AANA J.1999;67(1):49-52.

6. Solatpour F, Teymourian H, Mohajerani SA, Hoseinzadegan Shirazi F, Lotfollah Zadeh S, Baikpour M, et al. Comparison of the incidence of sore throat after rapid sequence intubation with succinylcholine and cisatracurium. Anesth Pain Med. 2014;4(3):e20030.

7. Tanaka Y, Nakayama T, Nishimori M, Sato Y, Furuya H. Lidocaine for preventing postoperative sore throat. Cochrane Database Syst Rev. 2009(3):CD004081.

8. Kalil DM, Silvestro LS, Austin PN. Novel preoperative pharmacologic methods of preventing postoperative sore throat due to tracheal intubation. AANA J. 2014;82(3):188-97.

9. Canbay O, Celebi N, Sahin A, Celiker V, Ozgen S, Aypar U. Ketamine gargle for attenuating postoperative sore throat. Br J Anaesth. 2008;100(4):490-3.

10. Shrestha SK, Bhattarai B, Singh J. Ketamine gargling and postoperative sore throat. JNMA J Nepal Med Assoc. 2010;50(180):282-5.

11. Rudra A, Ray S, Chatterjee S, Ahmed A, Ghosh S. Gargling with ketamine attenuates the postoperative sore throat. Indian J Anaesth. 2009;53(1):40-3.

12. Dahi-Taleghani M, Fazli B, Ghasemi M, Vosoughian M, Dabbagh A. Effect of intravenous patient controlled ketamine analgesiaon postoperative pain in opium abusers. Anesth Pain Med. 2014;4(1):e14129. 


\section{Teymourian Het al.}

13. Imani F, Faiz HR, Sedaghat M, Hajiashrafi M. Effects of adding ketamine to fentanyl plus acetaminophen on postoperative pain by patient controlled analgesia in abdominal surgery. Anesth Pain Med. 2014;4(1):e12162.

14. Shaaban AR, Kamal SM. Comparison between betamethasone gel applied over endotracheal tube and ketamine gargle for attenuating postoperative sore throat, cough and hoarseness of voice. Middle East J Anaesthesiol. 2012;21(4):513-9.

15. Borazan H, Kececioglu A, Okesli S, Otelcioglu S. Oral magnesium lozenge reduces postoperative sore throat: a randomized, prospective, placebo-controlled study. Anesthesiology. 2012;117(3):512-8.

16. Stenqvist O, Nilsson K. Postoperative sore throat related to tracheal tube cuff design. Can Anaesth Soc J.1982;29(4):384-6.
17. Moiniche S, Kehlet H, Dahl JB. A qualitative and quantitative systematic review of preemptive analgesia for postoperative pain relief: the role of timing of analgesia. Anesthesiology. 2002;96(3):725-41.

18. Maruyama K, Sakai H, Miyazawa H, Toda N, Iinuma Y, Mochizuki $\mathrm{N}$, et al. Sore throat and hoarseness after total intravenous anaesthesia. BrJ Anaesth. 2004;92(4):541-3.

19. Park SY, Kim SH, Noh JI, Lee SM, Kim MG, Kim SH, et al. The effect of intravenous low dose ketamine for reducing postoperative sore throat. Korean J Anesthesiol. 2010;59(1):22-6.

20. Piriyapatsom A, Dej-Arkom S, Chinachoti T, Rakkarnngan J, Srishewachart P. Postoperative sore throat: incidence, risk factors, and outcome. J Med Assoc Thai. 2013;96(8):936-42. 